\title{
The effect of clomiphene citrate, herbal mixture, and herbal mixture along with clomiphene citrate on clinical and para-clinical parameters in infertile women with polycystic ovary syndrome: a randomized controlled clinical trial
}

\author{
Nava Ainehchi', Arash Khaki ${ }^{1}$, Elaheh Ouladsahebmadarek ${ }^{1}$, Mohamad Hammadeh ${ }^{2}$, \\ Laya Farzadi ${ }^{1}$, Azizeh Farshbaf-Khalili ${ }^{3}$, Solmaz Asnaashari ${ }^{4}$, Hossein Jabbari Khamnei ${ }^{5}$, \\ Amir Afshin Khaki ${ }^{6}$, Majid Shokoohi ${ }^{6}$
}

\author{
'Women's Reproductive Health Research Center, Tabriz University of Medical \\ Sciences, Tabriz, Iran \\ 2Department of Obstetrics and Gynecology, University of Saarland, Homburg, \\ Germany \\ ${ }^{3}$ Aging Research Institute, Physical Medicine and Rehabilitation Research Centre, \\ Tabriz University of Medical Sciences, Tabriz, Iran \\ ${ }^{4}$ Biotechnology Research Center, Tabriz University of Medical Science, Tabriz, Iran \\ ${ }^{5}$ Department of Statistics, Faculty of Mathematical Sciences, Tabriz University, Tabriz, \\ Iran \\ ${ }^{6}$ Department of Anatomical Sciences, Faculty of Medicine, Tabriz University \\ of Medical Sciences, Tabriz, Iran
}

Submitted: 20 February 2019

Accepted: 3 August 2019

Arch Med Sci 2020; 16 (6): 1304-1318

DOI: https://doi.org/10.5114/aoms.2020.93271

Copyright $\odot 2020$ Termedia \& Banach

\begin{abstract}
Introduction: To evaluate the effect of a herbal mixture (i.e., Mentha spicata, Zingiber officinale, Cinnamomum zeylanicum, and Citrus sinensis) alone and in combination with clomiphene citrate (CC) compared to CC on the treatment of polycystic ovary syndrome (PCOS).

Material and methods: This single-blind randomized clinical trial was conducted on 60 infertile participants with PCOS who were randomly divided into three groups. After spontaneous or progestin-induced withdrawal bleeding, group $1(n=20)$ received routine treatment with CC $(50-150 \mathrm{mg})$ for three menstrual cycles from the $3^{\text {rd }}$ to $5^{\text {th }}$ day of menstruation for 5 days while group $2(n=20)$ and group $3(n=20)$ received herbal mixture capsules $700 \mathrm{mg} /$ day and the herbal mixture along with CC for 3 months, respectively. Finally, several related parameters were measured, including the level of sex steroids, homeostatic model assessment for insulin resistance (HOMA-IR), lipid profile (primary outcomes), thyroid hormones, and clinical features. The analysis was based on intention-to-treat analysis.

Results: No statistically significant differences were observed between the groups in terms of socio-demographic characteristics. However, after adjustment for baseline, luteinizing hormone $(\mathrm{aMD}=4.9 ; 95 \% \mathrm{Cl}$ : 3.7-6.2), luteinizing hormone/follicle-stimulating hormone $(\mathrm{aMD}=0.9 ; 95 \% \mathrm{Cl}: 0.7-1.2)$, total testosterone ( $\mathrm{aMD}=-0.12 ; 95 \% \mathrm{Cl}:-0.2$ to -0.01$)$ in group 2 and free testosterone $(\mathrm{aMD}=-6.0 ; 95 \% \mathrm{Cl}:-9.7$ to -2.3$)$ in group 3 revealed a significant difference compared to group 1 . In addition, HOMA-IR in group 2 $(\mathrm{aMD}=-1.3 ; 95 \% \mathrm{Cl}:-2.4$ to -0.2$)$ decreased significantly compared to group 1. Further, total cholesterol, triglycerides, low-density lipoprotein cholesterol, and very low-density lipoprotein cholesterol decreased significantly
\end{abstract}

\section{Corresponding author:} Elaheh Ouladsahebmadarek Women's Reproductive Health Research Center Tabriz University of Medical Sciences Tabriz, Iran

Phone: +98 9141144132

E-mail: ouladsahebmadarek@ tbzmed.ac.ir 
in group 2 ( $\mathrm{aMD}=-21.8 ; 95 \% \mathrm{Cl}:-31.5$ to $-12.1 ; \mathrm{aMD}=-29.9 ; 95 \% \mathrm{Cl}:-47.9$ to $-12.0 ; \mathrm{aMD}=-21.2 ; 95 \% \mathrm{Cl}$ : -31.3 to $-11.1 ; \mathrm{aMD}=-5.1 ; 95 \% \mathrm{Cl}:-7.5$ to -2.7$)$ and group $3(\mathrm{aMD}=-18.3 ; 95 \% \mathrm{Cl}:-27.4$ to $-9.2 ; \mathrm{aMD}=$ $-26.9 ; 95 \% \mathrm{Cl}:-43.8$ to -9.9 ; $\mathrm{aMD}=-21.4 ; 95 \% \mathrm{Cl}:-31.1$ to -11.7 ; $\mathrm{aMD}=-5.9 ; 95 \% \mathrm{Cl}:-8.3$ to -3.6$) \mathrm{com}-$ pared to group 1, respectively. However, high-density lipoproteins cholesterol in group 2 (aMD $=6.8 ; 95 \% \mathrm{Cl}$ : 2.9-10.7) and group 3 ( $\mathrm{aMD}=10.7 ; 95 \% \mathrm{Cl}: 7.2-14.7)$ increased remarkably compared to group 1. Overall, clinical outcomes improved significantly in all groups $(p<0.05)$.

Conclusions: In general, the herbal mixture along with CC was found to improve free testosterone, HOMA-IR, lipid profile, and clinical features of PCOS women.

Key words: clomiphene citrate, polycystic ovary syndrome, infertility, insulin resistance, hyperandrogenism, herbal mixture.

\section{Introduction}

Polycystic ovary syndrome (PCOS), as one of the most common female endocrine disorders, represents a leading cause of infertility with an incidence of $6-26 \%[1,2]$. Three criteria can be used to diagnose PCOS. The National Institute of Child Health and Human Development (NICHD) of the National Institutes of Health (NIH) in 1990 developed the oligo-ovulation, clinical or biochemical hyperandrogenism. In addition, the Rotterdam European Society for Human Reproduction (ESHRE)/American Society of Reproductive Medicine (ASRM) in 2003 established criteria such as oligo/amenorrhea, as well as the clinical and biochemical signs of hyperandrogenism and confirmed PCOS by ultrasonography. Two of the above-mentioned criteria are required for diagnosis. The Androgen Excess Society (AES) in 2006 defined androgen excess, along with various combinations of phenotypic features (e.g., hyperandrogenaemia, hirsutism, oligo-ovulation/anovulation, and/or polycystic ovaries) that could lead to more accurate diagnosis [3]. Although the clinical manifestation of PCOS may vary among women, hyperandrogenism and chronic anovulation are the main hallmarks of this disorder [4]. The androgen excess is manifested as hirsutism, acne/seborrhea while the chronic anovulation is manifested as oligomenorrhea/amenorrhea and reduction in fertility rate. Furthermore, PCOS is associated with dyslipidemia, obesity, insulin resistance, and multiple ovarian cysts [5]. The action of the gonadotropins, follicle-stimulating hormone (FSH), and luteinizing hormone (LH) regulates steroidogenesis [6]. However, excessive androgen production by the ovary is considered as the main physiological abnormality in women with PCOS. This pathway is driven by the enhanced pituitary-released $\mathrm{LH}$ secretion and increased theca cell sensitivity to gonadotropin stimulation [7]. Similarly, fast gonadotropin-releasing hormone $(\mathrm{GnRH})$ pulse frequencies, an increase in LH pulse frequency, and a reduction in FSH in PCOS patients contribute to impaired folliculogenesis and low levels of granulosa cell aromatase enzyme that are responsible for converting androgen precursors (e.g., androstenedione) to estrogen. Therefore, inadequate FSH leads to hyperandrogenism [8].

The growth of the ovarian follicle fails to succeed in completing its maturation for ovulation, and most follicles are arrested at the antral stage [9]. Moreover, hyperinsulinemia, as the main feature of PCOS, leads to the over-production of ovarian androgens [10] and has a negative impact on artery function and cardiovascular diseases [11]. In addition, it raises the levels of low-density lipoprotein cholesterol (LDL-C), very low-density lipoprotein cholesterol (VLDL-C), triglyceride (TG), and total cholesterol (TC) while decreasing the level of high-density lipoprotein cholesterol (HDL-C) [12]. The management of PCOS depends on the symptoms including menstrual disorders, ovulatory dysfunction-related infertility, or androgen-related symptoms. Several factors improve PCOS such as weight loss, clomiphene citrate (CC), gonadotropins (i.e., human menopausal gonadotropin (HMG) and FSH), and aromatase inhibitors (i.e., letrozole and anastrozole) by inducing ovulation. An antidiabetic agent (metformin), antiandrogens (spironolactone, flutamide, and finasteride), and oral contraceptives also play a role in this respect through decreasing insulin resistance, and androgen levels, as well as regulating menstrual periods, respectively [3]. Although PCOS is a metabolic disorder, the hypothalamic-pituitary axis is targeted as the firstline therapy. CC as a selective estrogen-receptor modulator, increases pituitary gonadotropin (i.e., FSH and $\mathrm{LH}$ ) release, promotes ovulation, and improves menstrual cycles by exerting negative feedback on the hypothalamus [13]. However, it may be associated with a number of side effects including the reduction in the endometrial thickness [14], nausea, vomiting, hot flashes, higher multiple pregnancy, breast discomfort, and ovarian hyperstimulation syndrome [13].

Recent studies have indicated that complementary medicine therapies such as herbal medicine have a potent effect on regulating $\mathrm{LH}, \mathrm{FSH}$, testosterone, fasting blood sugar (FBS), and insulin, and alleviate the symptoms of PCOS [15]. Furthermore, they can be counted as natural antioxidants 
that increase the rate of infertility and the level of serum antioxidants [16].

Cinnamomum zeylanicum Nees (cinnamon) from the Lauraceae family is shown to diminish insulin resistance by enhancing phosphatidylinositol 3-kinase activity in the insulin signaling pathway [17]. It not only increases glucose uptake but also reduces TG, LDL, and TC [18]. Additionally, cinnamon has polyphenolic polymers, including epicatechin, camphene, eugenol, $\gamma$-terpinene, phenol, salicylic acid, and tannin, that are potent antioxidants which promote glucose metabolism in people with diabetes [19]. Moreover, cinnamon enhances ovary function and improves menstrual cyclicity by gonadotropin stimulation [20].

Zingiber officinale Roscoe (ginger) from the Zingiberaceae family reduces the serum levels of FBS, TC, and TG while it enhances HDL [21]. In addition, it contains phenolic compounds such as zingerone, gingerols, and shogaols that are regarded as the main factors of antioxidant activity. These antioxidants prevent lipid oxidation and free-radical-induced diseases such as diabetes [22, 23]. 6-gingerol, as an active constituent of ginger, has anti-oxidant, anti-inflammatory, and anti-carcinogenic activity [24, 25]. Furthermore, ginger improves fertility by increasing antral follicle count, folliculogenesis, and implantation [26].

Citrus sinensis (L.) Osbeck from the Rutaceae family encompasses naringin and naringenin as two kinds of flavonoid which have anti-diabetic, anti-hyperlipidemic, and antioxidant properties [27, 28]. Further, the hydroethanolic extract of the $C$. sinensis peel improves insulin sensitivity by the expression of the insulin receptor, GLUT 4, and adiponectin [29]. C. sinensis has polymethoxylated flavones which demonstrate beneficial efficacy in glucose tolerance, lipid levels, and weight reduction [30].

Similarly, Mentha spicata (spearmint) from the Lamiaceae family, which is widespread in the temperate zone and has anti-androgen properties, decreases testosterone production, but it improves hirsutism and has anti-inflammatory, anti-diabetic, and anticancer effects as well [31]. Moreover, spearmint in PCOS improves ovarian cysts, reduces atretic follicles, and enhances Graafian follicles [32].

Although the aforementioned studies have demonstrated the potency of each herb, it is hypothesized that a mixture of these herbs could have a more potent impact on insulin resistance, lipid profile, and sex steroid regulation in PCOS patients. Therefore, the present study evaluated the effect of the "herbal mixture" and "herbal mixture, along with CC" in comparison with "CC" on serum HOMA-IR, sex steroids (i.e., FSH, LH, free testosterone (T), total testosterone (TT), and estradiol (E2)), and lipid profile (i.e., TC, TG, LDL-C, $\mathrm{HDL}-\mathrm{C}$, and VLDL-C) as the primary outcomes. The study further investigated the efficacy of these mixtures on thyroid hormones (i.e., thyroid-stimulating hormone (TSH), free thyroxine (FT4), free triiodothyronine (FT3)) and clinical features (i.e., hirsutism, acne, oligomenorrhea, amenorrhea, menstrual regulation, and the rate of pregnancy) as the secondary outcomes in PCOS patients.

\section{Material and methods}

\section{Study population}

A total of 60 women with polycystic ovary syndrome (PCOS) aged 18-35 years with primary and secondary infertility, as well as body mass index (BMI) between 26.5 and $28.5 \mathrm{~kg} / \mathrm{m}^{2}$, and willing to be pregnant, were included in this single-blind, parallel randomized clinical trial. The subjects were selected from the infertility clinic of Alzahra Hospital in Tabriz (Iran) and evaluated for approximately 9 months (from $16^{\text {th }}$ January 2016 to $25^{\text {th }}$ October 2016). The inclusion criteria were suffering from PCOS based on Rotterdam criteria (2003), having primary or secondary infertility, being within the age range of 18-35 years, and having a $\mathrm{BMI}<30 \mathrm{~kg} / \mathrm{m}^{2}$. The exclusion criteria included patients with diabetes mellitus, thyroid disorders, as well as the current use of medication such as helping ovulation or insulin sensitizers and cholesterol-lowering drugs, smoking, the current treatment of infertility, hypertension, cardiovascular diseases, Cushing's syndrome, and finally, allergy to spearmint, ginger, cinnamon, and C. sinensis.

The sample size was calculated as 20 individuals per group, 95\% confidence interval, $80 \%$ power, $\delta=0.5, \varepsilon=0.1$, and $\alpha=0.05$. The final sample was estimated as 25 women considering a $25 \%$ probable drop-out for each group.

The Ethics Committee of Tabriz University of Medical Science authorized the research protocol (Code: TBZMED.REC.1394.576) on 2015-11-26 and the research was certified in the Iranian Registry of Clinical Trial Website (IRCT201509295563N7) on 2016-01-09.

All study subjects were explained about the purpose of the study, and informed consent was obtained by a member of the research team. They were also asked to record their routine daily intake of food during 3 months of the study. Women were randomly allocated to three groups. After spontaneous or progestin-induced (a single intramuscular injection of $100 \mathrm{mg}$ progesterone at the end of the $35^{\text {th }}$ day of the menstrual cycle after a $\beta$-hCG test for ruling out the possibility of pregnancy) menstrual cycles, group $1(n=20)$ received routine treatment with a clomiphene citrate (CC) pill of 50-150 mg from day 3 to 5 of menstruation for 5 days. Group $2(n=20)$ consumed a $700 \mathrm{mg}$ 
herbal mixture capsule daily and group $3(n=20)$ used a $700 \mathrm{mg}$ herbal mixture capsule along with CC for 3 months. Additionally, the compliance of the subjects was followed up via phone consultation every week.

\section{Randomization}

The subjects were divided into three groups by using random allocation software (RAS, version 1.0.0) through randomized blocks of three and six with an allocation ratio of $1: 1: 1$ by a person who was not involved in the study. For allocation concealment, according to the sequence generation the opaque and sealed envelopes were numbered from 1 to 75 and the type of allocation was placed into these envelopes. The first envelope was dedicated to the first subject and this process continued up to the end of the research. It is worth mentioning that only the statistician was blind in this study.

\section{Data collection}

A socio-demographic and clinical feature questionnaire was developed to assess the age, marital age, weight, BMI, the history and type of infertility, hirsutism, acne, oligomenorrhea, and amenorrhea.

\section{Serum sample collection}

On the second day of the women's menstrual cycle, $10 \mathrm{ml}$ blood samples were collected twice before and after the intervention (3 months later) from antecubital veins in the morning after overnight fasting. The blood samples were then centrifuged for $10 \mathrm{~min}$ at $4000 \mathrm{rpm}$ in order to separate the serum. The extracted serum was divided into four aliquot samples and was frozen immediately at $-70^{\circ} \mathrm{C}$ until assay. All laboratory tests were conducted at the same laboratory and by an expert before and after the intervention.

\section{Sexual and thyroid hormone measurement}

The levels of FSH, LH, TT, and E2, as well as TSH, FT4, and FT3 were measured by the electrochemiluminescence (ECL) method using a Cobas E 411 analyzer (Germany).

\section{Free testosterone measurement}

The level of $T$ was determined by the ELISA method using a commercial kit (free testosterone: Monobind Inc., lake Forest, CA, USA).

\section{Insulin measurement}

Insulin was evaluated through a fully automated chemiluminescence assay (LIAISON C-Peptid, Byk-Sangtec) [33].

\section{Fasting blood sugar measurement}

Fasting blood sugar (FBS) was measured by enzymatic methods using commercial kits (Pars Azemun, Iran) and the auto-analyzer system (Selectra E, Vitalab, Netherland).

\section{HOMA-IR measurement}

The homeostatic model assessment of insulin resistance was calculated according to the HOMA-IR $=\frac{\text { Glucose } \times \text { Insulin }}{405}$ formula. The $75^{\text {th }}$ percentile of HOMA-IR in the whole population is 3.027, in normal weight 1.68 and obese 3.42 .

\section{Lipid profile measurement}

TC, TG, LDL, HDL, and VLDL were determined by an auto-analyzer system (Vita lab Selectra E, Netherlands).

\section{Ultrasonography}

The volume of the ovary, along with the numbers and the size of follicles, was probed by vaginal ultrasound ( $5 \mathrm{MHz}$ Ultramark 4 Plus; Advanced Technology Laboratories, Bothell, WA).

\section{Clinical Feature Checklist}

Information about acne and hirsutism were asked at the end of the 3-month treatment, amenorrhea and oligomenorrhea were followed up 3 months after the intervention, and finally, pregnancy was checked every 3 months of intervention and the checklists were filled out by the researcher.

\section{Side effects checklist}

A checklist on the side effects of the medications was given to the participants in order to complete during the intervention.

\section{Medicinal plants and capsule $(700 \mathrm{mg}$ ) preparation and standardization}

The dried plant samples consisting of the leaves of spearmint, the rhizomes of ginger, the bark of cinnamon, and the peels of $C$. sinensis were provided from the herbal medicine market and identified by the Department of Pharmacognosy, Faculty of Pharmacy, Tabriz University of Medical Sciences, Tabriz, Iran. Different plant samples were thoroughly powdered and sieved and the powders were mixed with $5(250 \mathrm{mg})$ : 4 (200 mg) : 3 (150 mg) : 2 (100 mg) weight ratios of spearmint, ginger, cinnamon, and $C$. sinensis, respectively.

Since antioxidant activity increased proportionally to the polyphenol component and had a tre- 
mendous effect on the treatment of PCOS, different proportions of each herb powder were mixed and then phenol and flavonoid were measured in the standardization of the herbal mixture. The highest levels of phenol and flavonoid were obtained in the weight ratios of $5(250 \mathrm{mg})$ spearmint: $4(200 \mathrm{mg})$ ginger : 3 (150 mg) cinnamon : 2 (100 mg) C. sinensis. Finally, the obtained ratio was used for the preparation of $700 \mathrm{mg}$ capsules. The lethal dose value (LD50) of cinnamon is $1850 \pm 37 \mathrm{mg} / \mathrm{kg}$ in the animals, which is equivalent to a human dose of $11.4 \pm 0.2 \mathrm{~g} / \mathrm{kg}$ [34] and that of $C$. sinensis, ginger, and spearmint is $4837.5 \mathrm{mg} / \mathrm{kg}$ [35], $5 \mathrm{~g} / \mathrm{kg}$ [36], and $5000 \mathrm{mg} / \mathrm{kg}$ [37], respectively.

\section{Total phenol content (TPC)}

The total amount of the phenolic components was determined by the Folin-Ciocalteu method. About $1 \mathrm{ml}$ of methanolic extract $(5 \mathrm{mg} / \mathrm{ml}$ in acetone-water solution) was mixed with $200 \mu$ of Folin-Ciocalteu reagent and $1 \mathrm{ml}$ of $2 \% \mathrm{Na}_{2} \mathrm{CO}_{3}$ and the new solution was incubated for $30 \mathrm{~min}$ at room temperature. Then, the absorbance was determined at $750 \mathrm{~nm}$ using a spectrophotometer (Spectronic Genesys 5). Various concentrations of gallic acid were used as the standard while the control samples contained no extract. All evaluations were performed in triplicate.

\section{Total flavonoid content (TFC)}

The total flavonoids were estimated using the $\mathrm{AlCl}_{3}$ method. 80\% methanol was applied as the test solution. In addition, $133 \mathrm{mg}$ of crystalline $\mathrm{AlCl}_{3}$ and $400 \mathrm{mg}$ of crystalline $\mathrm{NaCOOCH}_{3}$ were dissolved in $100 \mathrm{ml}$ of $80 \%$ methanol and used as the $\mathrm{AlCl}_{3}$ reagent. To estimate the flavonoid content of the extract, $2 \mathrm{ml}$ of the extract solution, $400 \mu \mathrm{l}$ of water, and $1 \mathrm{ml}$ of the $\mathrm{AlCl}_{3}$ reagent were mixed and the absorbance was set at $430 \mathrm{~nm}$ using a spectrophotometer (Spectronic Genesys 5). The blank solution containing no $\mathrm{AlCl}_{3}$ reagent and with different concentrations of quercetin were utilized as the standard. The amount of flavonoids was estimated according to the calibration curve of the quercetin as well. All measurements were performed in triplicate.

\section{Statistical analysis}

Descriptive statistics, including the frequency and percentage, and the measures of central tendency and dispersion, namely, the mean and standard deviation, were employed to describe the study variables. The results were analyzed using one-way ANOVA by post-hoc Tukey test for the baseline quantitative variables. The paired $t$-test was applied to compare quantitative data before and after the trial within the three groups and ANCOVA was used for be- tween-group analysis after the intervention adjusted for baseline values. In addition, between-group analysis for nominal and rating variables was performed by $\chi^{2}$ and independent samples Kruskal-Wallis tests and within-group comparisons were conducted by Mann-Whitney $U$ and Wilcoxon signed rank tests. A $p$-value $\leq 0.05$ was considered statistically significant. The data were analyzed using SPSS software, version 22 (SPSS Inc., Chicago, IL, USA).

\section{Results}

The initial sample included 90 women with PCOS, but 11 of them were excluded because they did not meet the Rotterdam criteria and 4 women's husbands suffered from azoospermia. Then, 75 participants were randomly allocated to three groups including CC, herbal mixture, and $\mathrm{CC}$ with the herbal mixture, each containing 25 women. Next, 22/25 women in group 1, 23/25 women in group 2, and 24/25 women in group 3 received the allocated intervention. However, 3,2 , and 1 of them in groups 1,2 , and 3 felt no comfort for participation, respectively. During the follow-up stage, one subject in group 1 was lost to follow-up because of consuming other medications along with the treatment and one of them became pregnant. Further, two subjects in group 2 discontinued the intervention on account of deciding to initiate treatment with IUI or IVF and one of them became pregnant, and finally, two subjects in group 3 decided on IUI or IVF treatment and two of them became pregnant. Eventually, 60 women ( $n=20$ in each group) completed the intervention and were analyzed at the end of 3 months (Figure 1).

Before the intervention, there were no significant differences between the groups in terms of socio-demographic characteristics. The mean \pm standard deviation (SD) of age in groups 1, 2, and 3 was $25.0 \pm 3.8,26.2 \pm 4.4$, and $25.7 \pm 4.2$ years, respectively. About $15 \%$ of women in group 1 and 2 versus $5 \%$ in group 3 had a history of abortion. Furthermore, the number of cases of primary and secondary infertility was $18(90 \%)$ and $2(10 \%)$ in group 1, $16(80 \%)$ and 4 (20\%) in group 2, and 19 (95\%) and 1 (5\%) in group 3, respectively. None of the subjects were smokers (Table I).

Moreover, no significant differences were observed between the groups regarding the serum levels of FSH $(p=0.626)$, LH $(p=0.989), \mathrm{LH} / \mathrm{FSH}$ $(p=0.676), \mathrm{T}(p=0.466), \mathrm{TT}(p=0.775)$, and E2 ( $p=0.266)$ before the intervention. Conversely, a significant difference was found between the groups respecting $\mathrm{LH}(p<0.001), \mathrm{LH} / \mathrm{FSH}(p<$ $0.001), \mathrm{T}(p<0.001)$, and TT ( $p=0.018)$ except for E2 $(p=173)$ and FSH $(p=0.152)$ after the intervention with adjustment of baseline values. In binary comparison, the level of LH $(\mathrm{aMD}=4.9 ; 95 \% \mathrm{Cl}$ : 


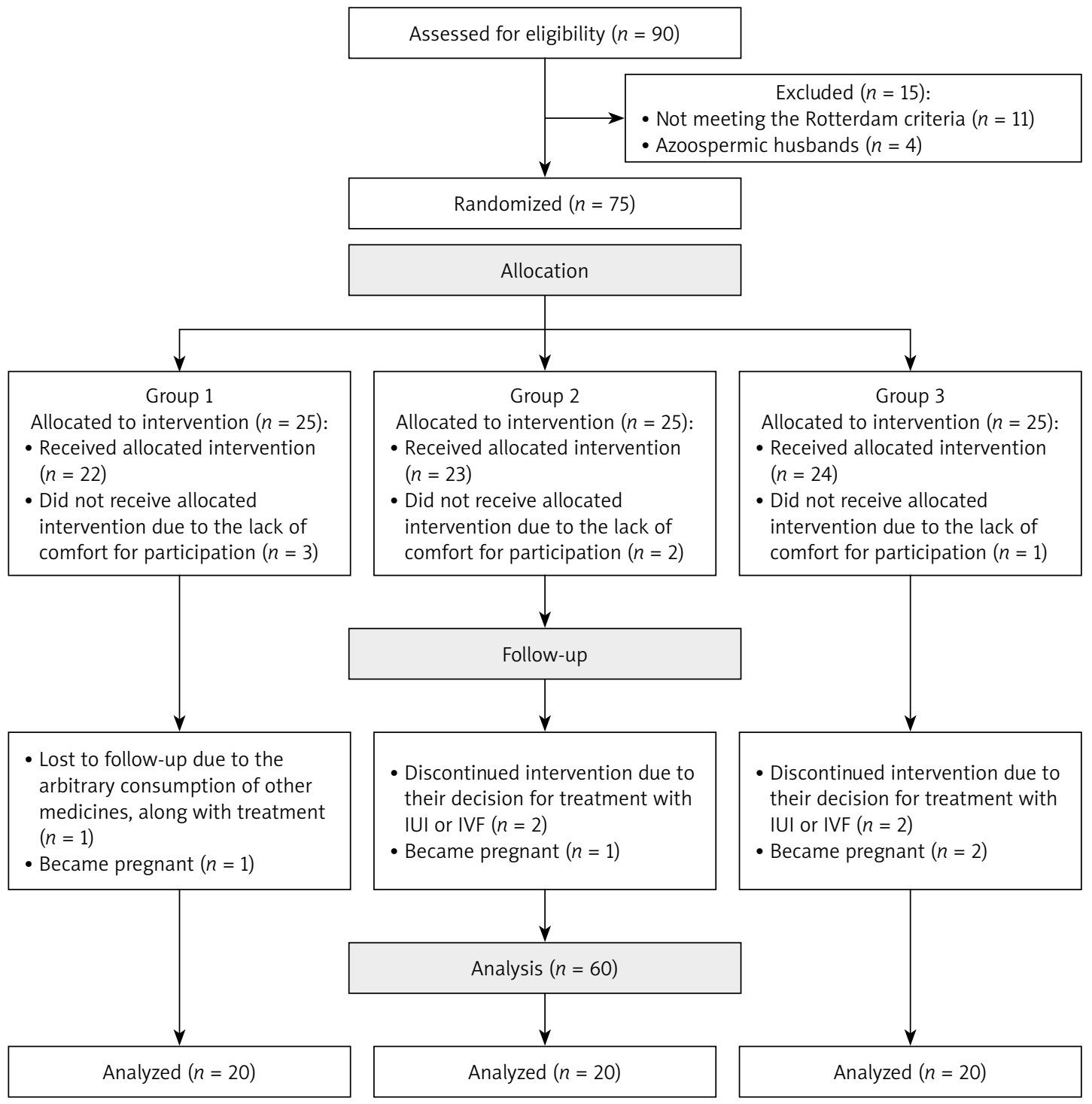

Figure 1. Flow diagram of polycystic ovary syndrome (PCOS) patients

Group 1 - clomiphene citrate (CC), group 2 - herbal mixture, group 3 - CC along with herbal mixture.

3.7-6.2, $p<0.001)$ and LH/FSH (aMD = 0.9; 95\% Cl: 0.7-1.2, $p<0.001)$ in group 2 indicated a significant difference in comparison with group 1 as well. Additionally, the level of TT in group 2 and the level of $T$ in group 3 were decreased ( $\mathrm{AMD}$ $=-0.12 ; 95 \% \mathrm{Cl}:-0.2$ to $-0.01, p=0.022)$ and (aMD $=-6.0 ; 95 \% \mathrm{Cl}:-9.7$ to $-2.3, p<0.001)$, which were significant compared to group 1. However, the level of FSH in both groups $2(p=0.831)$ and $3(p=0.545)$, the level of LH in group $3(p=0.999)$, the level of LH/FSH in group $3(p=0.973)$, the level of T in group $2(p=0.204)$, the level of TT in group 3 ( $p=0.099)$, and the level of E2 in both groups 2 $(p=0.995)$ and $3(p=0.332)$ were not significant compared to group 1. In within-group analysis, there was a significant decrease in terms of $\mathrm{LH}$ in group $1(\mathrm{MD}=-7.5 ; 95 \% \mathrm{Cl}:-9.7$ to $-5.2, p<$ 0.001 ), group 2 ( $M D=-2.4 ; 95 \% \mathrm{Cl}:-2.9$ to -1.9 , $p<0.001)$, and group 3 (MD $=-7.6 ; 95 \% \mathrm{Cl}:-9.6$ to $-5.5, p<0.001)$ after the intervention compared to the baseline. In addition, the level of $\mathrm{LH} /$ $\mathrm{FSH}$ in group 1 ( $\mathrm{MD}=-2.3 ; 95 \% \mathrm{Cl}:-2.9$ to -1.6 , $p<0.001)$, group $2(\mathrm{MD}=-1.0 ; 95 \% \mathrm{Cl}:-1.2$ to -0.8 , $p<0.001)$, and group $3(\mathrm{MD}=-2.2 ; 95 \% \mathrm{Cl}:-2.8$ to $-1.7, p<0.001$ ) decreased significantly. Further, a significant decline was detected in the level of $T$ only in group 3 (MD $=-6.7 ; 95 \% \mathrm{Cl}$ : -9.5 to -3.9 , $p<0.001$ ), as well as the level of TT only in group 2 $(\mathrm{MD}=-0.08 ; 95 \% \mathrm{Cl}:-0.13$ to $-0.03, p=0.003)$. However, the level of FSH in group $1(\mathrm{MD}=0.9$; 95\% Cl: 0.7-1.2, $p<0.001)$, group $2(M D=0.9$; $95 \% \mathrm{Cl}: 0.7-1.2, p<0.001)$, and group $3(\mathrm{MD}=0.8$; $95 \% \mathrm{Cl}: 0.4-1.1, p<0.001)$ in addition to the level of E2 in group 1 (MD $=7.5 ; 95 \% \mathrm{Cl}$ : 3.5-11.4, $p<0.001)$, group $2(\mathrm{MD}=9.9 ; 95 \% \mathrm{Cl}: 6.1-13.9$, $p<0.001)$, and group $3(\mathrm{MD}=10.8 ; 95 \% \mathrm{Cl}: 5.8-$ $15.8, p<0.001)$ significantly increased compared to the baseline. Moreover, there were no signifi- 
N. Ainehchi, A. Khaki, E. Ouladsahebmadarek, M. Hammadeh, L. Farzadi, A. Farshbaf-Khalili, S. Asnaashari, H.J. Khamnei, A.A. Khaki, M. Shokoohi

Table I. General characteristics of the women with PCOS at baseline and after the intervention

\begin{tabular}{|c|c|c|c|c|}
\hline Variable & $\begin{array}{l}\text { Group } 1 \\
(n=20)\end{array}$ & $\begin{array}{l}\text { Group } 2 \\
(n=20)\end{array}$ & $\begin{array}{l}\text { Group } 3 \\
(n=20)\end{array}$ & $P$-value \\
\hline \multicolumn{5}{|l|}{ Maternal data: } \\
\hline Age, mean (SD) [years] & $25.0(3.8)$ & $26.2(4.4)$ & $25.7(4.2)$ & $0.685^{\dagger}$ \\
\hline $20-25, n(\%)$ & $14(70)$ & $8(40)$ & $12(60)$ & $0.288^{\S}$ \\
\hline $26-30, n(\%)$ & $4(20)$ & $10(50)$ & $5(25)$ & \\
\hline $31-35, n(\%)$ & $2(10)$ & $2(10)$ & $3(15)$ & \\
\hline Marital age, mean (SD) [years] & $20.7(3.7)$ & $20.1(3.7)$ & $19.7(2.9)$ & $0.689^{\dagger}$ \\
\hline History of infertility, mean (SD) [years] & $3.1(1.4)$ & $4.3(4.2)$ & $4.2(2.7)$ & $0.374^{\dagger}$ \\
\hline History of abortion, $n$ (\%) & $3(15)$ & $3(15)$ & $1(5)$ & $0.481^{\S}$ \\
\hline Weight, baseline, mean (SD) [kg] & $72.8(11.7)$ & $76.0(11.0)$ & $72.6(11.6)$ & $0.597^{\dagger}$ \\
\hline BMI, baseline, mean (SD) $\left[\mathrm{kg} / \mathrm{m}^{2}\right]$ & $27.1(4.1)$ & $28.5(3.4)$ & $26.9(3.9)$ & $0.415^{\dagger}$ \\
\hline BMI, after intervention, mean (SD) $\left[\mathrm{kg} / \mathrm{m}^{2}\right]$ & $26.9(0.2)$ & $27.0(0.2)$ & $26.8(0.2)$ & $0.770^{\mathrm{A}}$ \\
\hline Type of infertility, $n$ (\%): & & & & $0.250^{\S}$ \\
\hline Primary & $18(90)$ & $16(80)$ & $19(95)$ & \\
\hline Secondary & $2(10)$ & $4(20)$ & $1(5)$ & \\
\hline Smoking, none, $n(\%)$ & $20(100)$ & $20(100)$ & $20(100)$ & \\
\hline
\end{tabular}

${ }^{\dagger}$ One-way ANOVA, ' Fisher's exact test, ${ }^{A}$ Analysis of covariance for between groups; group 1 - clomiphene citrate (CC), group 2 - herbal mixture, group 3-CC with herbal mixture (Clomiphene: Control).

cant alterations between the groups regarding the $\mathrm{T}$ in groups 1 and 2, as well as TT in groups 1 and 3 ( $p>0.05)$, the details of which are shown in Table II.

Table III presents the results related to the effect of CC, herbal mixture, and CC along with herbal mixture on HOMA-IR, TC, TG, LDL-C, HDL-C, VLDL-C, TSH, Free T4, and Free T3. Based on the findings, the serum levels of HOMA-IR $(p=0.188)$ and lipid profile including TG $(p=0.061)$, LDL-C $(p=0.070)$, HDL-C $(p=0.176)$, and VLDL-C ( $p=$ $0.311)$ were not significantly different except for TC $(p=0.031)$ before the intervention. However, the results showed a significant difference regarding the HOMA-IR $(p=0.017)$, TC $(p<0.001)$, TG $(p<0.001)$, LDL-C $(p<0.001)$, HDL-C $(p<0.001)$, and VLDL-C $(p<0.001)$ after the intervention with adjustment for baseline values. Conversely, there were no significant differences between the groups ( $p>0.05$ ) with regard to TSH, FT4, and FT3 before and after the intervention. In binary comparison, the level of HOMA-IR indicated a significant decrease in group $2(\mathrm{aMD}=-1.3 ; 95 \% \mathrm{Cl}:-2.4$ to $-0.2, p=0.013$ ) in comparison with group 1 . Moreover, as regards the lipid profile, the level of TC in group 2 (aMD $=-21.8 ; 95 \% \mathrm{Cl}$ : -31.5 to $-12.1, p<0.001)$ and group $3(\mathrm{aMD}=-18.3$; $95 \% \mathrm{Cl}:-27.4$ to $-9.2, p<0.001)$, the level of TG in group 2 (aMD $=-29.9 ; 95 \% \mathrm{Cl}:-47.9$ to $-12.0, p<$ $0.001)$ and group 3 (aMD $=-26.9 ; 95 \% \mathrm{Cl}:-43.8$ to $-9.9, p<0.001$ ), the level of LDL-C in group 2
$(\mathrm{aMD}=-21.2 ; 95 \% \mathrm{Cl}:-31.3$ to $-11.1, p<0.001)$ and group 3 (aMD $=-21.4 ; 95 \% \mathrm{Cl}:-31.1$ to -11.7 , $p<0.001)$, as well as the level of VLDL-C in group 2 (aMD $=-5.1 ; 95 \% \mathrm{Cl}:-7.5$ to $-2.7, p<0.001)$ and group 3 (aMD $=-5.9 ; 95 \% \mathrm{Cl}:-8.3$ to -3.6 , $p<0.001)$ decreased significantly. Contrarily, the level of HDL-C in group 2 (aMD $=6.8 ; 95 \% \mathrm{Cl}: 2.9-$ $10.7, p<0.001)$ and group $3(\mathrm{aMD}=10.7 ; 95 \% \mathrm{Cl}$ : 7.2-14.7, $p<0.001$ ) increased significantly compared to group 1. However, there were no remarkable changes in the level of HOMA-IR in group 3 ( $p=0.403$ ) and thyroid hormones including TSH in group $2(p=0.973)$ and group $3(p=0.949)$, FT4 in group $2(p=0.809)$ and group $3(p=1)$, and finally, FT3 in group $2(p=0.940)$ and group 3 ( $p=0.864)$ compared to group 1 . In within-group analysis, a significant reduction was observed after the intervention in terms of HOMA-IR in group $2(\mathrm{MD}=-1.0 ; 95 \% \mathrm{Cl}:-1.7$ to $-0.4, p=0.002)$, as well as lipid profiles such as TC in group 2 $(\mathrm{MD}=-27.6 ; 95 \% \mathrm{Cl}:-36.2$ to $-19.0, p<0.001)$ and group 3 ( $\mathrm{MD}=-22.2 ; 95 \% \mathrm{Cl}:-28.9$ to -15.4 , $p<0.001)$, TG in group $2(\mathrm{MD}=-50.7 ; 95 \% \mathrm{Cl}$ : -73.8 to $-27.6, p<0.001)$ and group $3(\mathrm{MD}=$ $-39.4 ; 95 \% \mathrm{Cl}:-56.2$ to $-22.4, p<0.001)$, the level of LDL-C in group 2 (MD $=-25.6 ; 95 \% \mathrm{Cl}:-34.2$ to $-17.0, p<0.001)$ and group $3(\mathrm{MD}=-24.9$; $95 \% \mathrm{Cl}:-32.9$ to $-16.9, p<0.001)$, and the level of VLDL-C in group 2 (MD $=-7.3 ; 95 \% \mathrm{Cl}:-10.4$ to $-4.2, p<0.001)$ and group $3(\mathrm{MD}=-7.7 ; 95 \% \mathrm{Cl}$ : 


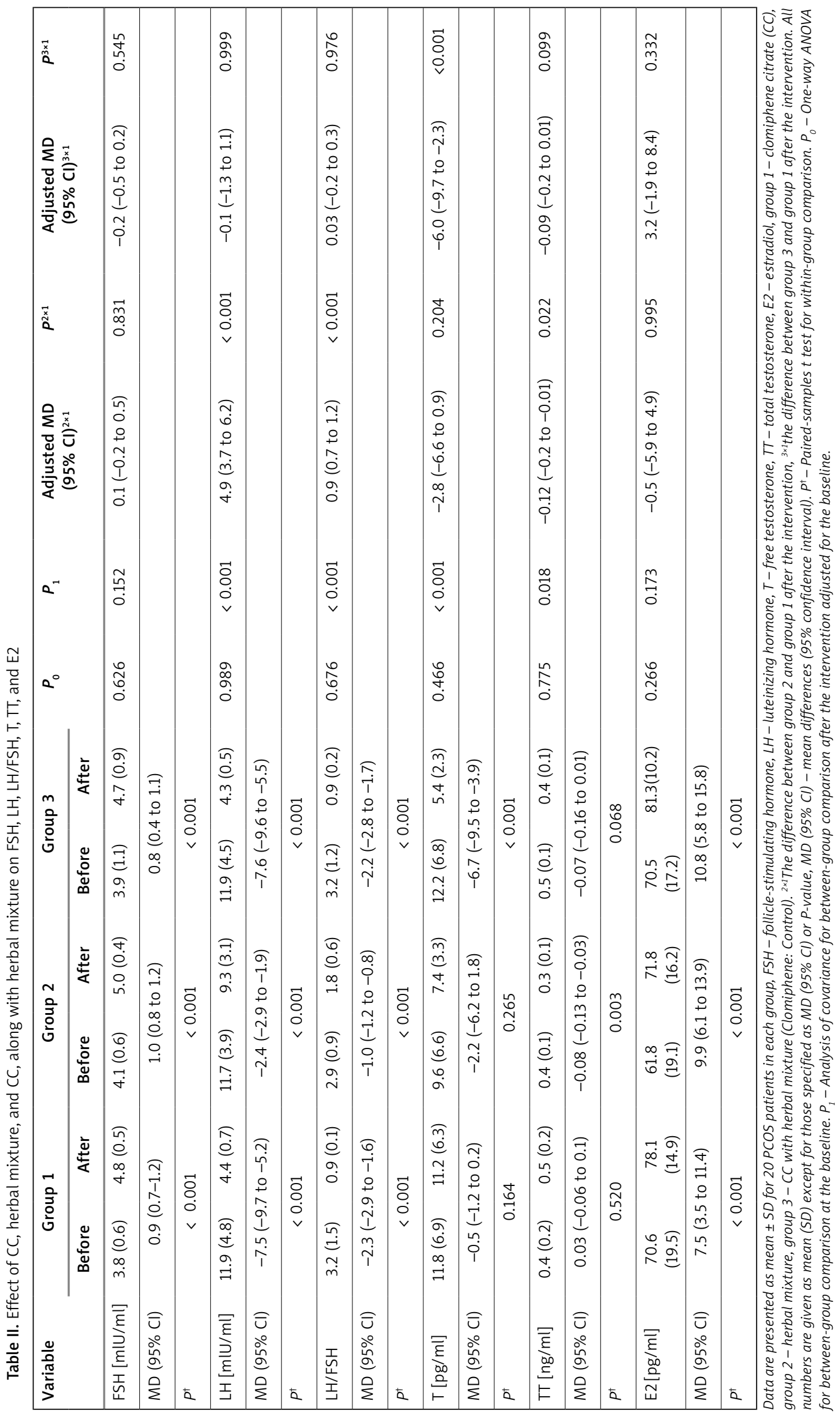


N. Ainehchi, A. Khaki, E. Ouladsahebmadarek, M. Hammadeh, L. Farzadi, A. Farshbaf-Khalili, S. Asnaashari, H.J. Khamnei, A.A. Khaki, M. Shokoohi

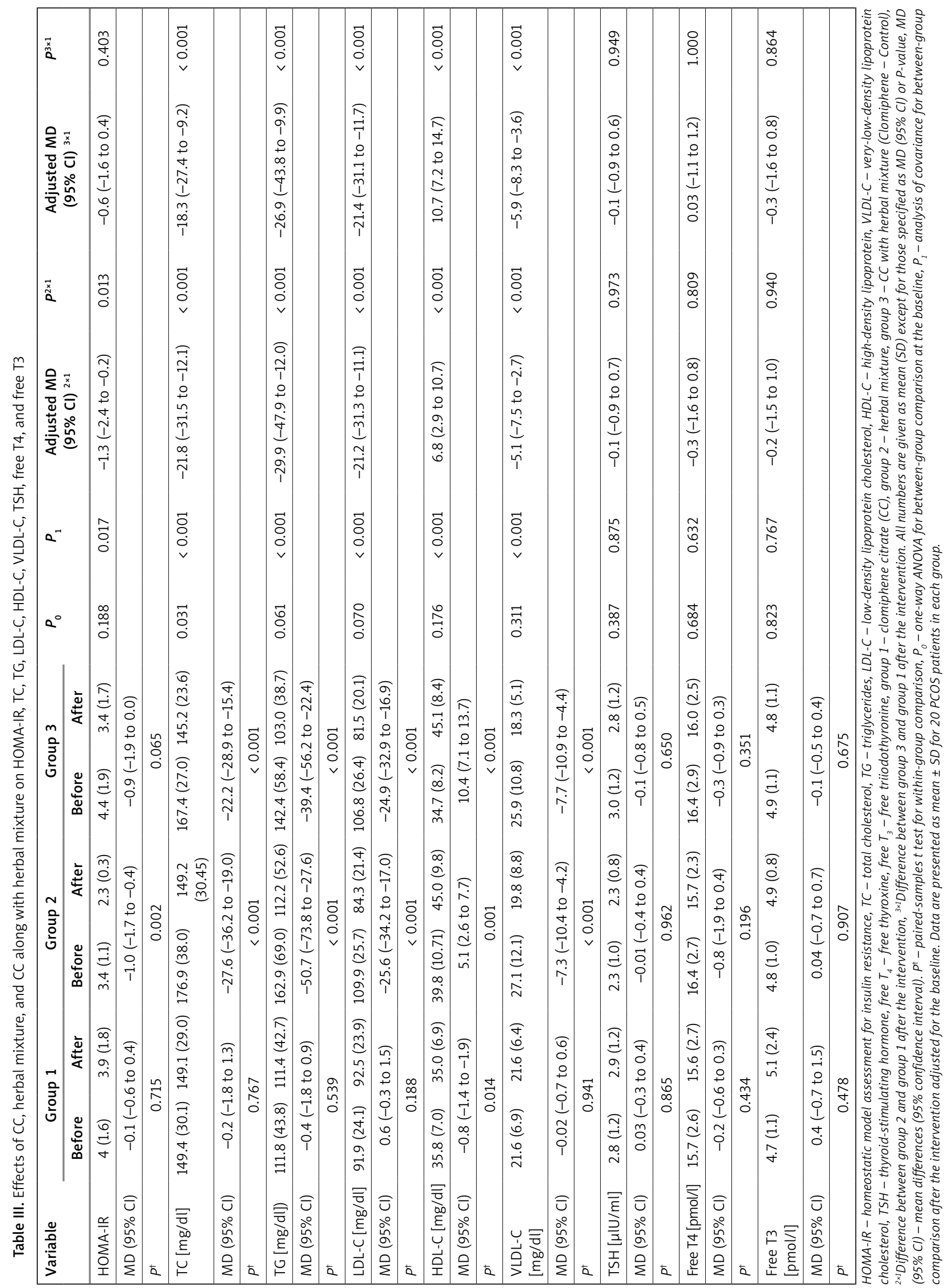


-10.9 to $-4.4, p<0.001)$ compared to the baseline. However, the level of HDL-C increased significantly in both groups 2 (MD $=5.1 ; 95 \% \mathrm{Cl}: 2.6-7.7$, $p<0.001)$ and $3(\mathrm{MD}=10.4 ; 95 \% \mathrm{Cl}: 7.1-13.7$, $p<0.001)$. Overall, there was no significant intra-group alteration regarding the HOMA-IR, TC, TG, LDL-C, and VLDL-C in group $1(p>0.05)$, as well as TSH, FT3, and FT4 in all three groups $(p>0.05)$.

According to the obtained data regarding the frequency of acne in 60 PCOS patients before and after the intervention (Table IV), acne significantly improved after the 3-month intervention in comparison with the baseline in all three groups $(p=$ $0.011, p=0.008$, and $p<0.001$ for groups 1,2 , and 3 , respectively). However, no significant difference was found between the groups before and after the intervention due to a parallel reduction among the groups $(p>0.05)$.

In the case of hirsutism, a considerable number of patients improved significantly in group 1 $(p=0.023)$, group $2(p=0.001)$, and group $3(p=$ $0.001)$. Although there was no significant difference between the groups before the intervention, the difference among the groups became significant after the treatment $(p<0.001)$, the related data are provided in Table $\mathrm{V}$.

Table VI presents the amount of amenorrhea and oligomenorrhea in 60 PCOS patients in three groups over 3 months. In group 1, 31.3\% (vs. $65 \%$ at the baseline), and in group 2, $20 \%$ (vs. $55 \%$ at the baseline) of the subjects had oligomenorrhea after the intervention $(p=0.014$ and $p=0.014$, respectively). In addition, $33.3 \%$ of the subjects of group 3 suffered from oligomenorrhea (vs. 100\% at the baseline) after the intervention ( $p<0.001$ ). Furthermore, $25 \%$ (vs. $45 \%$ at the baseline) of the subjects in group 1 and $26.7 \%$ (vs. $65 \%$ at the baseline) of them in group 3 had amenorrhea ( $p=0.46$ and $p=0.005$, respectively) while $13.4 \%$ (vs. $35 \%$ at the baseline) of the subjects of group 2 suffered from amenorrhea, but the difference between the groups was not significant $(p=0.083)$.

The ultrasonography criteria for PCOS women indicated no significant variations in the number, the size of basal antral follicle count (AFC), and the volume of the ovary in all three groups on the second day of the menstruation cycle after the three-month treatment, which were 10-12, 2-12 $\mathrm{mm}$, and $10 \mathrm{~cm}^{3}$, respectively. Meanwhile, sonography in the mid-cycle of the third month showed that in group 1, the antral follicles of $14 / 20$ patients reached the ovulation stage and four of them became pregnant (18.2\%). In group 2, 11/20 PCOS women showed dominant follicles and two of them got pregnant (8.7\%). Finally, in group 3, 17/20 PCOS subjects had dominant follicles $(18-20 \mathrm{~mm})$ which resulted in five pregnancies $(20.8 \%$, one of which was a twin pregnancy).

No side effects were reported in all three study groups during the 12-week intervention, the compliance was good and the subjects consumed the prescribed supplements during the study period.

Eventually, the assessment of TPC and TFC contents proved the presence of $24.062 \pm 0.2 \mathrm{mg}$ gallic acid/100 mg and $8.93 \pm 0.09 \mathrm{mg}$ quercetin/ $100 \mathrm{mg}$ in the herbal mixture.

Table IV. Frequency of acne in 60 PCOS patients in three groups during 3 months

\begin{tabular}{|c|c|c|c|c|}
\hline Groups & Acne & Before, $n(\%)$ & After, $n(\%)$ & $P^{\epsilon}$ \\
\hline \multirow{4}{*}{$\begin{array}{l}\text { Group 1 } \\
(n=20)\end{array}$} & None & $11(55)$ & $13(65)$ & \multirow[t]{4}{*}{0.011} \\
\hline & Mild & $3(15)$ & $6(30)$ & \\
\hline & Moderate & $5(25)$ & $1(5)$ & \\
\hline & Severe & $1(5)$ & $0(0)$ & \\
\hline \multirow{4}{*}{$\begin{array}{l}\text { Group } 2 \\
(n=20)\end{array}$} & None & $8(40)$ & $12(60)$ & \multirow[t]{4}{*}{0.008} \\
\hline & Mild & $3(15)$ & $5(25)$ & \\
\hline & Moderate & $7(35)$ & $2(10)$ & \\
\hline & Severe & $2(10)$ & $1(5)$ & \\
\hline \multirow{4}{*}{$\begin{array}{l}\text { Group } 3 \\
(n=20)\end{array}$} & None & $9(45)$ & $12(60)$ & \multirow[t]{4}{*}{0.001} \\
\hline & Mild & 3 (15) & $7(35)$ & \\
\hline & Moderate & $6(30)$ & $1(5)$ & \\
\hline & Severe & $2(10)$ & $0(0)$ & \\
\hline$P^{£}$ & & 0.550 & 0.878 & \\
\hline
\end{tabular}

Group 1 - clomiphene citrate (CC), group 2 - herbal mixture, group 3 - CC with herbal mixture (Clomiphene: Control); ${ }^{\text {independent }}$

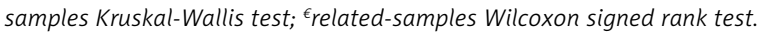


N. Ainehchi, A. Khaki, E. Ouladsahebmadarek, M. Hammadeh, L. Farzadi, A. Farshbaf-Khalili, S. Asnaashari, H.J. Khamnei, A.A. Khaki, M. Shokoohi

Table V. Percentage of hirsutism in 60 PCOS patients in three groups during 3 months

\begin{tabular}{|c|c|c|c|c|}
\hline Groups & Hirsutism & Before, $n(\%)$ & After, $n(\%)$ & $P^{€}$ \\
\hline \multirow{4}{*}{$\begin{array}{l}\text { Group } 1 \\
(n=20)\end{array}$} & None & $4(20)$ & $6(30)$ & 0.023 \\
\hline & Mild & $6(30)$ & $8(40)$ & \\
\hline & Moderate & $4(20)$ & $2(10)$ & \\
\hline & Severe & $6(30)$ & $4(20)$ & \\
\hline \multirow{4}{*}{$\begin{array}{l}\text { Group } 2 \\
(n=20)\end{array}$} & None & $7(35)$ & $16(80)$ & 0.001 \\
\hline & Mild & $9(45)$ & $4(20)$ & \\
\hline & Moderate & $1(5)$ & $0(0)$ & \\
\hline & Severe & $3(15)$ & $0(0)$ & \\
\hline \multirow{4}{*}{$\begin{array}{l}\text { Group } 3 \\
(n=20)\end{array}$} & None & $3(15)$ & $7(35)$ & 0.001 \\
\hline & Mild & $6(30)$ & $11(55)$ & \\
\hline & Moderate & $4(20)$ & $2(10)$ & \\
\hline & Severe & $7(35)$ & $0(0)$ & \\
\hline$p^{£}$ & & 0.094 & 0.001 & \\
\hline
\end{tabular}

Group 1 - clomiphene citrate (CC), group 2 - herbal mixture, group 3 - CC with herbal mixture (Clomiphene: Control); ${ }^{\text {tindependent }}$

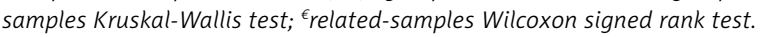

Table VI. Frequency of amenorrhea and oligomenorrhea in 60 PCOS patients in three groups during 3 months

\begin{tabular}{|c|c|c|c|c|c|c|c|c|}
\hline \multirow[t]{2}{*}{ Groups } & & \multicolumn{3}{|c|}{ Amenorrhea } & \multicolumn{3}{|c|}{ Oligomenorrhea } & \multirow{2}{*}{$\begin{array}{c}\text { Pregnancy } \\
\text { After } \\
n(\%)\end{array}$} \\
\hline & & $\begin{array}{c}\text { Before } \\
n(\%)\end{array}$ & $\begin{array}{l}\text { After } \\
n(\%)\end{array}$ & $P^{\epsilon}$ & $\begin{array}{c}\text { Before } \\
n(\%)\end{array}$ & $\begin{array}{l}\text { After } \\
n(\%)\end{array}$ & $p^{\epsilon}$ & \\
\hline \multirow[t]{2}{*}{ Group 1} & Yes & $9(45)$ & $4(25)$ & 0.046 & $13(65)$ & $5(31.3)$ & 0.014 & $4(18.2)$ \\
\hline & No & $11(55)$ & $12(75)$ & & $7(35)$ & $11(68.7)$ & & $18(81.8)$ \\
\hline \multirow[t]{2}{*}{ Group 2} & Yes & 7 (35) & $2(13.4)$ & 0.083 & $11(55)$ & $3(20)$ & 0.014 & $2(8.7)$ \\
\hline & No & $13(65)$ & $13(86.6)$ & & $9(45)$ & $12(80)$ & & 21 (91.3) \\
\hline \multirow[t]{2}{*}{ Group 3} & Yes & $13(65)$ & $4(26.7)$ & 0.005 & $20(100)$ & $5(33.3)$ & $<0.001$ & $5(20.8)$ \\
\hline & No & 7 (35) & $11(73.3)$ & & $0(0)$ & $10(66.7)$ & & $19(79.2)$ \\
\hline$P^{ \pm}$ & & 0.145 & 0.784 & & 0.004 & 0.628 & & 0.546 \\
\hline
\end{tabular}

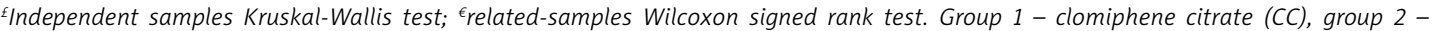
herbal mixture, group 3-CC along with herbal mixture (Clomiphene: Control); Amenorrhea and oligomenorrhea criteria were followed up 3 months after the intervention among women who received no treatment or failed to become pregnant. Pregnancy was determined during a 3-month intervention among women who received the intervention.

\section{Discussion}

This study was conducted to investigate the effect of a herbal mixture, CC, and the herbal mixture along with CC on clinical and para-clinical parameters in infertile women with PCOS. According to the results, the potency of $\mathrm{CC}$ was much greater in reducing the serum level of $\mathrm{LH}$ and $\mathrm{LH} / \mathrm{FSH}$, which were measured on the $2^{\text {nd }}$ day of the menstrual cycle, compared to the herbal mixture. In addition, the reduction in level of $\mathrm{T}$ in the group of subjects who consumed CC along with the herbal mixture was more significant in comparison with CC. However, the level of TT decreased notably in the herbal mixture group compared to CC.
In fact, hyperinsulinemia, as one of the significant features in the development of PCOS, stimulates androgen production through 3 mechanisms. First, hyperinsulinemia increases the circulation of $T$ by reducing the concentration of serum sex hormone-binding globulin (SHBG), which is a glycoprotein that binds to $T$ [38]. Then, hyperinsulinemia increases the synthesis of androgens by enhancing the activity of cytochrome P450c-17 $\alpha$ in PCOS women [39]. Finally, insulin decreases the insulin-like growth factor binding protein-1 (IGFBP-1) synthesis, which results in greater availability of insulin-like growth factor in the ovary, thus boosting the androgen production via theca-interstitial and stromal cells [40]. In PCOS, the hypo- 
thalamic-pituitary-ovarian axis is implicated and the disturbance in the pulsatility of GnRH causes a relative increase of $\mathrm{LH}$ to $\mathrm{FSH}$. Also, the abnormal feedback mechanism by ovarian estrogen is probably responsible for increasing the $\mathrm{LH}$ release [41].

CC is a nonsteroidal selective estrogen-receptor modulator that inhibits the estrogen receptors in the hypothalamus, as well as the negative feedback effect of the estrogen on gonadotropin release, leading to the up-regulation of the hypothalamic-pituitary-gonadal axis [42]. Further, CC, as the first-line therapy for ovulation induction, still has a high failure rate. However, CC usage for more than six cycles was found to have a high risk of ovarian cancer in these patients [43]. Therefore, in the current study, as in a previous study [44], herbal-mediated supplementation along with CC was used as complementary medicine that might reduce the treatment duration while increasing the efficacy.

Heibashy et al. reported that cinnamon extract reduced $\mathrm{T}$ [45]. Anti-androgenic effects of spearmint decreased the levels of $\mathrm{LH}$, as well as free and TT as well [31]. Ginger plays a crucial role in the improvement of PCOS through reducing $T$ and $\mathrm{LH}$ and improving ovulation [46]. Furthermore, at higher doses, ginger was found to have similar efficacy as CC but without any side effects. Moreover, it can be used as an effective and good alternative for improving PCOS by decreasing the $\mathrm{LH}$ and estrogen while notably increasing progesterone and FSH concentrations [47]. The findings of all the above-mentioned studies are in line with the results of the current study.

Additionally, our results clearly demonstrated that the level of HOMA-IR decreased more significantly in the group that consumed the herbal mixture in comparison with CC. Moreover, the level of lipid profile (TC, TG, LDL-C, VLDL-C) in both the herbal mixture and CC along with herbal mixture groups decreased significantly. However, the level of HDL-C increased remarkably as compared to CC.

In fact, high blood glucose induces reactive oxidative stress (ROS), which results in the derivation of superoxide [48]. As a consequence, reactive species play a key role in insulin resistance by impairing the glucose uptake and reducing the insulin secretion from pancreatic $\beta$ cells [49].

Furthermore, insulin resistance inhibits hepatic lipase activity in the liver and reduces hormone-sensitive lipase in adipose tissue, leading to the release of free fatty acids and inflammatory cytokines such as interleukin 6 (IL-6), tumor necrosis factor $\alpha$ (TNF- $\alpha$ ), and leptin [50].

One study claimed that cinnamon polyphenols and proanthocyanidin content have an insulin-like and hypoglycemic effect and thus induce the pancreas to release insulin [51]. The reductive effects of cinnamon on total cholesterol and FBS levels in type II diabetes patients were proven as well [52]. Additionally, it was shown that the phenolic compound of spearmint has reducing power, possesses hypoglycemic, hypocholesterolemic, and antioxidant attributes, and increases the HDL level [53]. In addition, polyphenols from ginger, including gingerols and shogaols, have antidiabetic potency [54]. Based on the results of another study, ginger possesses hypoglycemic, hypolipidemic, and hypocholesterolemic potential. In other words, the mechanism of the hypoglycemic action of ginger might be due to serotonin receptors that activate the $\beta$-cells of the pancreas in order to release insulin [55]. Polymethoxylated flavones of C. sinensis improve the insulin resistance by regulating the adipocytokines [56]. It has been shown that $C$. sinensis has the potential for lowering the cholesterol, TG, and LDL levels, as well as raising the HDL level [57]. Particularly, Khaki et al. used a combination of ginger and cinnamon in diabetic male rats and found that FBS and insulin levels decreased more significantly compared to the other groups, which consumed only one herb [58]. Each of these herbs has the potential for reducing insulin resistance, as well as the lipid profile, and in the present study, the same results were obtained in the mixture model as well.

Recent research has confirmed that vitamin $D_{3}$ supplementation has a beneficial effect on $\mathrm{HOMA}^{3}$ IR and dyslipidemia [59]. Furthermore, in one of the latest studies comparing the HOMA-IR method and insulin resistance (Belfiore) index, it was concluded that insulin resistance (Belfiore) index diagnosed more cases of insulin resistance in women with PCOS compared to HOMA-IR [60].

Likewise, the analysis of clinical features demonstrated that after the 12-week intervention, the frequency of hirsutism and acne improved in all three groups. Moreover, oligomenorrhea and amenorrhea criteria improved compared to the baseline. The pregnancy rate occurred in all three groups during the 3-month intervention as well.

The reduction of sensitivity of pre-antral follicles to FSH or the enhancement of the follicular activity of LH leading to the inhibition of follicle maturation is considered as the main cause of PCOS [61]. Similarly, the excessive secretion of LH and $\mathrm{GnRH}$ stimulates the ovarian theca cells in order to produce androgens [62]. As a result, hyperandrogenism not only arrests the antral follicle growth but also stimulates apoptosis of its granulose cells which converts androgen to estradiol by aromatase enzyme [63]. On the other hand, the interaction of LH with insulin leads to the improper differentiation of granulosa cells and arrests the follicle growth and ovulation and causes irregular menses [64]. 
According to Kort et al. cinnamon improved ovulatory menses by enhancing progesterone levels in the luteal phase of PCOS women [20]. Similarly, spearmint, by reducing the level of $T$ and having antioxidant properties, matured follicles and induced ovulation, and also improved hirsutism [32]. Additionally, Matiz et al. reported the antimicrobial activity of $C$. sinensis and sweet basil in treating acne [65]. Ginger not only stimulates blood circulation for the treatment of inflammation but also has good effects in relieving menstrual dysmenorrhea and irregularities [66]. Jiang et al. further showed that ginger enhanced the AFC and ovarian reserve [67]. CC stimulates ovulation and increases the fertility rate by stimulating $\mathrm{GnRH}$ secretion and an anti-estrogenic effect as well [68].

The results of the present study indicate that a herbal mixture such as the combination of CC with herbal mixture decreases the lipid profile. Additionally, CC regulates sex steroids while not interfering with the lipolysis effect of the herbal mixture.

One of the strong points of this study was to evaluate the effect of the herbal mixture, alone and in combination with CC compared to CC, on clinical and para-clinical parameters in infertile PCOS women. Furthermore, in previous studies, the effects of all the aforementioned herbs were investigated separately whereas in this study we measured a mixture of such herbs as a new combination that might have synergistic effects.

This study had some limitations including its small sample population, the evaluation of oxidative stress, and short duration of the study. Therefore, further studies are needed to evaluate the effects of this mixture on longer duration and variable doses of the herbal mixture at larger sample size, and prescribe a healthy diet and exercise alongside intervention. Moreover, more cellular and molecular studies are required to elucidate the underlying mechanisms of each herb or their mixture in ameliorating hormonal disturbances in PCOS.

In conclusion, the herbal mixture reduces HOMA-IR. In addition, both the herbal mixture and the combination of CC with herbal mixture reduce lipid profile, and $\mathrm{CC}$ regulates the levels of $\mathrm{LH}, \mathrm{FSH}$, and LH/FSH. Further, the herbal mixture and the combination of CC with herbal mixture reduce total testosterone and free testosterone, respectively, and each group improves the clinical features. The rate of pregnancy in the combination of CC with the herbal mixture was higher than that of the remaining groups. This herbal mixture could be used as a supplement in treating PCOS disorders without side effects. Considering the fact that hyperinsulinemia is one of the significant features in the development of PCOS, the use of herbal mixture alongside CC could be an appropriate complementary therapy in infertile PCOS patients.

\section{Acknowledgments}

Trial registration: IRCT201509295563N7. Registered 9 January 2016, https://www.irct.ir/trial/5976.

This research was funded by Tabriz University of Medical Sciences, Tabriz, Iran (grant number: 5.4.9505), as well as Iran National Science Foundation (INSF) and the Deputy of Research and Technology of Ministry of Health and Medical Education (grant number: 96010160).

We acknowledge the Pharmaceutical Aras Part Medicinal Herbs International Company for preparing the herbal mixture capsules, Women's Reproductive Health Research Center, Tabriz University of Medical Sciences, Tabriz, Iran for their infertility clinic, as well as Iran National Science Foundation (INSF) and the Deputy of Research and Technology of Ministry of Health and Medical Education for financial support. Our further appreciation goes to all investigators, coordinators, and patients who assisted or took part in this study.

\section{Conflict of interest}

The authors declare no conflict of interest.

\section{References}

1. Szczuko M, Skowronek M, Zapalowska-Chwyc M, Starczewski A. Quantitative assessment of nutrition in patients with polycystic ovary syndrome (PCOS). Rocz Państ Zakł Hig 2016; 67: 419-26.

2. Ozcan Dag Z, Alpua M, Isik Y, Buturak SV, Tulmac OB, Turkel Y. The evaluation of temperament and quality of life in patients with polycystic ovary syndrome. Gynecol Endocrinol 2017; 33: 250-3.

3. Badawy A, Elnashar A. Treatment options for polycystic ovary syndrome. Int J Women's Health 2011; 3: 25-35.

4. Franks S. Polycystic ovary syndrome. N Engl J Med 1995; 333: 853-61.

5. Al Awlaqi A, Alkhayat K, Hammadeh ME. Metabolic syndrome and infertility in women. Int J Womens Health Reprod Sci 2016; 4: 89-95.

6. Tayyar AT, Kahraman S. Comparison between cycles of the same patients when using recombinant luteinizing hormone + recombinant follicle stimulating hormone (rFSH), human menopausal gonadotropin + rFSH and rFSH only. Arch Med Sci 2019; 15: 673-9.

7. Rosencrantz MA, Coffler MS, Haggan A, et al. Clinical evidence for predominance of delta-5 steroid production in women with polycystic ovary syndrome. J Clin Endocrinol Metabol 2011; 96: 1106-13.

8. McCartney CR, Eagleson CA, Marshall JC. Regulation of gonadotropin secretion: implications for polycystic ovary syndrome. Semin Reprod Med 2002; 20: 317-26.

9. Hosseini E, Shahhoseini M, Afsharian P, et al. Role of epigenetic modifications in the aberrant CYP19A1 gene 
expression in polycystic ovary syndrome. Arch Med Sci 2019; 15: 887-95.

10. Baptiste CG, Battista MC, Trottier A, Baillargeon JP. Insulin and hyperandrogenism in women with polycystic ovary syndrome. J Steroid Biochem Mol Biol 2010; 122 $42-52$.

11. Xue W, Li Y, Li J, Yan L, Yang F. Endothelium-dependent relaxation induced by etomidate in the aortas of insulin-resistant rats. Arch Med Sci 2018; 14: 1155-62.

12. Banaszewska B, Duleba AJ, Spaczynski RZ, Pawelczyk L Lipids in polycystic ovary syndrome: role of hyperinsulinemia and effects of metformin. Am J Obstet Gynecol 2006; 194: 1266-72.

13. Behnoud N, Farzaneh F, Ershadi S. The effect of clomiphene citrate versus letrozole on pregnancy rate in women with polycystic ovary syndrome: a randomized clinical trial. Crescent J Med Biol Sci 2019; 6: 335-40.

14. Ghomian N, Khadem N, Moeindarbari S, Abdolrazagh A Comparison of pregnancy rate in patients with polycys tic ovary syndrome treated with clomiphene alone and in combination with $\mathrm{N}$-acetyl cysteine: a randomized clinical trial. Int J Womens Health Reprod Sci 2019; 7: 185-9.

15. Abtahi-Eivari SH, Moghimian M, Soltani $M$, et al. The effect of Galega officinalis on hormonal and metabolic profile in a rat model of polycystic ovary syndrome. Int J Womens Health Reprod Sci 2018; 6: 276-82.

16. Shokoohi M, Madarek EOS, Khaki A, et al. Investigating the effects of onion juice on male fertility factors and pregnancy rate after testicular torsion/detorsion by intrauterine insemination method. Int J Womens Health Reprod Sci 2018; 6: 499-505.

17. Wang JG, Anderson RA, Graham III GM, et al. The effect of cinnamon extract on insulin resistance parameters in polycystic ovary syndrome: a pilot study. Fertil Steril 2007; 88: 240-3.

18. Khodaeifar F, Fazljou SMB, Khaki A, et al. Investigating the role of hydroalcoholic extract of apium graveolens and cinnamon zeylanicum on metabolically change and ovarian oxidative injury in a rat model of polycystic ovary syndrome. Int J Womens Health Reprod Sci 2019; 7: 92-8.

19. Anderson RA, Broadhurst CL, Polansky MM, et al. Iso lation and characterization of polyphenol type-A polymers from cinnamon with insulin-like biological activity. J Agric Food Chem 2004; 52: 65-70.

20. Kort DH, Lobo RA. Preliminary evidence that cinnamon improves menstrual cyclicity in women with polycystic ovary syndrome: a randomized controlled trial. Am J Obstet Gynecol 2014; 211: 487.e1-6.

21. Jafarnejad S, Keshavarz SA, Mahbubi S, et al. Effect of ginger (Zingiber officinale) on blood glucose and lipid concentrations in diabetic and hyperlipidemic subjects: a meta-analysis of randomized controlled trials. J Funct Foods 2017; 29: 127-34.

22. Höferl M, Stoilova I, Wanner J, et al. Composition and comprehensive antioxidant activity of ginger (Zingiber officinale) essential oil from Ecuador. Nat Prod Commun 2015; 10: 1085-90.

23. Afshari AT, Shirpoor A, Farshid A, et al. The effect of ginger on diabetic nephropathy, plasma antioxidant capacity and lipid peroxidation in rats. Food Chem 2007; 101 148-53.

24. Rhode J, Fogoros S, Zick S, et al. Ginger inhibits cell growth and modulates angiogenic factors in ovarian cancer cells. BMC Complementary Altern Med 2007; 7: 44.

25. Lee SH, Cekanova M, Baek SJ. Multiple mechanisms are involved in 6-gingerol-induced cell growth arrest and apoptosis in human colorectal cancer cells. Mol Carcinogen 2008; 47: 197-208.

26. Yılmaz N, Seven B, Timur H, et al. Ginger (zingiber officinale) might improve female fertility: a rat model. J Chin Med Assoc 2018; 81: 905-11.

27. Ahmed OM, Moneim AA, Yazid IA, Mahmoud AM. Antihyperglycemic, antihyperlipidemic and antioxidant effects and the probable mechanisms of action of Ruta graveolens infusion and rutin in nicotinamide-streptozotocin-induced diabetic rats. Diabetol Croatica 2010; 39: $15-35$.

28. Constantin RP, Constantin RP, Bracht A, Yamamoto NS, Ishii-Iwamoto EL, Constantin J. Molecular mechanisms of citrus flavanones on hepatic gluconeogenesis. Fitoterapia 2014; 92: 148-62.

29. Ahmed OM, Hassan MA, Abdel-Twab SM, Azeem MNA. Navel orange peel hydroethanolic extract, naringin and naringenin have anti-diabetic potentials in type 2 diabetic rats. Biomed Pharmacother 2017; 94: 197-205.

30. Oben J, Enonchong E, Kothari S, Chambliss W, Garrison R, Dolnick D. Phellodendron and Citrus extracts benefit joint health in osteoarthritis patients: a pilot, double-blind, placebo-controlled study. Nutr J 2009; 8: 38.

31. Grant P. Spearmint herbal tea has significant anti-androgen effects in polycystic ovarian syndrome. A randomized controlled trial. Phytother Res 2010; 24: 186-8.

32. Abasian Z, Rostamzadeh A, Mohammadi M, Hosseini M, Rafieian-Kopaei M. A review on role of medicinal plants in polycystic ovarian syndrome: pathophysiology, neuroendocrine signaling, therapeutic status and future prospects. Middle East Fertility Soc J 2018; 23: 255-62.

33. Pfützner A, Löbig M, Fortunato A, Forst T. Evaluation of a new fully automated one-step C-peptide chemiluminescence assay (LIAISON C-Peptid). Clin Labor 2003; 49: 227-32.

34. Ranasinghe P, Galappaththy P, Constantine GR, et al. Cinnamomum zeylanicum (Ceylon cinnamon) as a potential pharmaceutical agent for type-2 diabetes mellitus: study protocol for a randomized controlled trial. Trials 2017; 18: 446.

35. Li Y, Kandhare AD, Mukherjee AA, Bodhankar SL. Acute and sub-chronic oral toxicity studies of hesperidin isolated from orange peel extract in Sprague Dawley rats. Regul Toxicol Pharmacol 2019; 105: 77-85.

36. Sharifi-Rad M, Varoni E, Salehi B, et al. Plants of the genus Zingiber as a source of bioactive phytochemicals: from tradition to pharmacy. Molecules 2017; 22: E2145.

37. Naidu JR, Ismail R, Sasidharan S. Acute oral toxicity and brine shrimp lethality of methanol extract of Mentha Spicata L (Lamiaceae). Trop J Pharmaceut Res 2014; 13: 101-7.

38. Nestler JE, Powers LP, Matt DW, et al. A direct effect of hyperinsulinemia on serum sex hormone-binding globulin levels in obese women with the polycystic ovary syndrome. J Clin Endocrinol Metabolism 1991; 72: 83-9.

39. De Leo V, La Marca A, Ditto A, Morgante G, Cianci A. Effects of metformin on gonadotropin-induced ovulation in women with polycystic ovary syndrome. Fertil Steril 1999; 72: 282-5.

40. LeRoith D, Werner H, Beitner-Johnson D, Roberts Jr CT. Molecular and cellular aspects of the insulin-like growth factor I receptor. Endocr Rev 1995; 16: 143-63.

41. Alnakash AH, Al-Tae e NK. Polycystic ovarian syndrome: the correlation between the LH/FSH ratio and disease manifestations. Middle East Fertility Soc J 2007; 12: 35-40. 
42. DrugBank. Clomifene Archived 2011-06-27. Available from: http://www.drugbank.ca/drugs/DB00882.

43. Ayaz A, Alwan Y, Farooq MU. Metformin-clomiphene citrate vs. clomiphene citrate alone: polycystic ovarian syndrome. J Human Reproduct Sci 2013; 6: 15-8.

44. Khaki A, Ainehchi N. Herbal medicine and sexual behavior in diabetic patients. Int J Womens Health Reprod Sci 2017; 5: 1-2.

45. Heibashy M, Mazen G, Shahin M. Metabolic changes and hormonal disturbances in polycystic ovarian syndrome rats and the amelioration effects of metformin and/or cinnamon extraction. J Am Sci 2013; 9: 54-62.

46. Pournaderi PS, Hejazi SH, Yaghmaei P, Khodaei H, Noormohammadi Z. Comparing the therapeutic effects of 6-gingerol and hydro-alcoholic extract of ginger on polycystic ovary syndrome in Wistar rat. Adv Herbal Med 2017; 3: 33-41.

47. Atashpour S, Jahromi HK, Jahromi ZK, Maleknasab M. Comparison of the effects of Ginger extract with clomiphene citrate on sex hormones in rats with polycystic ovarian syndrome. Int J Reprod BioMed 2017; 15: 561-8.

48. Giacco F, Brownlee M. Oxidative stress and diabetic complications. Circul Res 2010; 107: 1058-70.

49. Nolan CJ, Prentki M. The islet beta-cell: fuel responsive and vulnerable. Trends Endocrinol Metabol 2008; 19 285-91.

50. Ormazabal V, Nair S, Elfeky O, Aguayo C, Salomon C, Zuñiga FA. Association between insulin resistance and the development of cardiovascular disease. Cardiovasc Diabetol 2018; 17: 122

51. Cheng DM, Kuhn P, Poulev A, Rojo LE, Lila MA, Raskin I. In vivo and in vitro antidiabetic effects of aqueous cinnamon extract and cinnamon polyphenol-enhanced food matrix. Food Chem 2012; 135: 2994-3002.

52. Khan A, Safdar M, Khan MMA, Khattak KN, Anderson RA. Cinnamon improves glucose and lipids of people with type 2 diabetes. Diabetes Care 2003; 26: 3215-8.

53. Bayani M, Ahmadi-hamedani M, Javan AJ. Study of hypoglycemic, hypocholesterolemic and antioxidant activities of Iranian Mentha spicata leaves aqueous extract in diabetic rats. Iran J Pharm Res 2017; 16 (Suppl): 75.

54. Kazeem MI, Akanji MA, Yakubu MT. Amelioration of pancreatic and renal derangements in streptozotocin-induced diabetic rats by polyphenol extracts of Ginger (Zingiber officinale) rhizome. Pathophysiology 2015; 22: 203-9.

55. Al-Amin ZM, Thomson M, Al-Qattan KK, Peltonen-Shalaby R, Ali M. Anti-diabetic and hypolipidaemic properties of ginger (Zingiber officinale) in streptozotocin-induced diabetic rats. Br J Nutr 2006; 96: 660-6.

56. Li RW, Theriault AG, Au K, et al. Citrus polymethoxylated flavones improve lipid and glucose homeostasis and modulate adipocytokines in fructose-induced insulin resistant hamsters. Life Sci 2006; 79: 365-73.

57. Mallick N, Khan RA. Antihyperlipidemic effects of Citrus sinensis, Citrus paradisi, and their combinations. J Pharm Bioallied Sci 2016; 8: 112-8.

58. Khaki A, Khaki AA, Hajhosseini L, Golzar FS, Ainehchi N. The anti-oxidant effects of ginger and cinnamon on spermatogenesis dys-function of diabetes rats. African J Tradit Complem Altern Med 2014; 11: 1-8.

59. Imga NN, Karci AC, Oztas D, Berker D, Guler S. Effects of vitamin $\mathrm{D}$ supplementation on insulin resistance and dyslipidemia in overweight and obese premenopausal women. Arch Med Sci 2019; 15: 598-606.

60. Lewandowski KC, Skowrońska-Jóźwiak E, Łukasiak K, et al. How much insulin resistance in polycystic ovary syndrome? Comparison of HOMA-IR and insulin resistance (Belfiore) index models. Arch Med Sci 2019; 15: 613-8.

61. Dupont J, Scaramuzzi RJ. Insulin signalling and glucose transport in the ovary and ovarian function during the ovarian cycle. Biochem J 2016; 473: 1483-501.

62. Gilling-Smith C, Story H, Rogers V, Franks S. Evidence for a primary abnormality of thecal cell steroidogenesis in the polycystic ovary syndrome. Clin Endocrinol 1997; 47: 93-9.

63. Azhary JM, Harada M, Takahashi N, et al. Endoplasmic reticulum stress activated by androgen enhances apoptosis of granulosa cells via induction of death receptor 5 in PCOS. Endocrinology 2018; 160: 119-32.

64. Franks S, Robinson S, Willis DS. Nutrition, insulin and polycystic ovary syndrome. Rev Reprod 1996; 1: 47-53.

65. Matiz G, Osorio MR, Camacho F, Atencia M, Herazo J. Effectiveness of antimicrobial formulations for acne based on orange (Citrus sinensis) and sweet basil (Ocimum basilicum L) essential oils. Biomedica 2012; 32 125-33.

66. Rahnama P, Fallah Huseini $\mathrm{H}$, Mohammadi $\mathrm{H}$, et al. The effects of Zingiber officinal R. On primary dysmenorrhea. J Med Plants 2010; 4: 81-6.

67. Jiang D, Zhang Y, Wu X, Wang Y, Fan Q, Wu S. Effects of ginger-separated moxibustion at Baliao points combined with Bushen Huoxue formula on patients with decreased ovarian reserve function. Zhongguo Zhen Jiu 2017; 37: 1057-60.

68. Brown J, Farquhar C. Clomiphene and other antioestrogens for ovulation induction in polycystic ovarian syndrome. Cochrane Database Syst Rev 2016; 12 CD002249. 